\title{
Production of English Syllable Final /1/ by Mandarin Chinese Speakers
}

\author{
Yunjuan $\mathrm{He}$ \\ Department of Modern and Classical Languages, University of North Georgia, Dahlonega, USA
}

\begin{abstract}
This study examined the production of English syllable final $/ / / \mathrm{s}$ by Chinese speakers. It was found that 1) Chinese speakers had great difficulties in producing syllable final /l/. 2) More importantly, Chinese speakers used three strategies to modify syllable final /l/: vocalization, deletion, and retroflexion. Among the strategies, vocalization is used to modify the syllable final /// after front and back vowels, while deletion and retroflexion occur only after back vowels. Furthermore, vocalization and retroflexion occurred after the back vowels more frequently in formal speech than in casual speech. 3) Experienced ESL learners produced more native-like syllable final $/ \mathrm{l} / \mathrm{s}$ than inexperienced ones, and females produced accurate or near accurate syllable final $/ /$ more frequently than males.
\end{abstract}

Index Terms -second language phonology, production, English syllable-final ///

\section{INTRODUCTION}

It is well known that most adult second language (L2) speakers retain an accent when speaking an L2, even when they can speak the L2 with grammatical correctness and functional fluency. The accent can usually be detected in both vowels and consonants, and may frequently break down communication. With regard to consonants, both prevocalic and postvocalic consonants can be problematic, but the postvocalic ones (i.e., in coda position) seem especially so.

\section{A. Previous Studies on English Consonants in Coda Position}

Many studies have been conducted over the past two decades to explore how L2 speakers acquire English consonants. It has been found that native Mandarin and Korean speakers devoiced final stops (Hansen, 2001; Major \& Faudree 1996; Wang, 1995). Native Mandarin speakers replaced the interdental fricatives / $\theta$, $/$ / with /s, z/, respectively (Hansen, 2001). Native Korean speakers inserted the vowel [1 ] after the palatal fricative / $/$ and affricates /t $\int$, d $3 /$ (Schmidt \& Meyer, 1995; Yeon, 2004). Native Japanese speakers confused nasal /n/ with nasal /n/ (Aoyama, 2003). As well, ESL speakers simplified English consonant clusters using epenthesis, deletion or feature changing strategies (Broselow et al., 1998; Major, 1994; Major \& Kim, 1999; Weinberger, 1987). In contrast, one area in the L2 consonant research that seems to have not attracted comparable attention is the second language production of the liquid /1/. Among the limited studies on /1/, most have been focused on the syllable-initial /1/ (Bradlow et al., 1997, 1999; Borden et al., 1983; Goto, 1971; Sheldon et al., 1982, 1985) or its perception in relation to another liquid /r/ by Japanese speakers (Aoyama et al., 2004).

However, very few studies have been undertaken to systematically describe how L2 speakers acquire the English liquid /l/ in coda position. In an investigation of the English syllable final /l/ produced by Korean-English bilingual children, Oh (2002) found that the tip of the tongue gesture was produced earlier by the Korean-English bilingual children than the one by English monolingual children. The Korean-English bilingual children also had an additional gesture in their production, raising the tongue body, a gesture used in producing the Korean /1/. Thus, the result was a clear indication that L1 transfer had played a role in the L2 acquisition. Heselwood and McChrystal (2000) studied teenage Punjabi-English bilinguals and found that these teenagers tended to use a palatalized /l/ to produce the syllabic $/ / 1 /$ in a word like candle. They also added a vowel $/ \varepsilon /$ before the palatalized /l/, which is very different from the midcentral schwa-type vowel found in monolingual English in these environments. The researchers did not however explain why the subjects made such a modification of syllabic /l/. The last two decades witnessed an unprecedented increase in the number of native Mandarin speakers learning English as a second language. However, only two studies addressed the difficulties that Mandarin speakers had in pronouncing the syllable-final /l/. Lee (1976), for instance, mentioned that the native Mandarin speakers had trouble with the $/ 1 /$, but he fell short of describing how the speakers exhibited such difficulties. Hansen (2001) conducted another study which pointed out that the syllable-final /1/ in the word tell was one of the most difficult consonants for Mandarin speakers. He found that the $/ 1 /$ was absent in $23 \%$ of their production and that $8 \%$ of their production involved feature change. Hansen also did not go further to examine closely the nature of the problem.

\section{B. English /l/}

English /1/ occurs in three different syllable positions. They are syllable-initial /1/, as in lip $/ \mathrm{l} \mathrm{p} /$, syllable final $/ 1 /$, as in peel /pi:1/ and syllabic /l/, as in people /pi:pl/. Traditionally, syllable initial /// is called light L or clear L (Hattori, 1984; Bladon \& Al-Bamerni, 1976), while syllable final /l/ and syllabic /l/ are called dark L. In Sproat and Fujimura's 
(1993) study, they used the terms "prevocalic L" and "postvocalic L" to describe syllcoable initial /1/ and syllable final /1/, respectively. For the purposes of this study, the phoneme /1/ will be categorized by its syllable positions.

According to Sproat and Fujimura's (1993) study, "All productions of /1/ involve two gestures, one gesture corresponding to the apical extension, henceforth termed the apical gesture, and the other corresponding to the dorsal retraction and lowering, the dorsal gesture. The apical gesture of /1/ is a consonantal gesture and the dorsal retraction gesture is a vocalic gesture since it does not produce a radical constriction in the vocal tract" (p. 304). "Consonantal gestures tend to be stronger in syllable initial position and weaker in syllable final position. Vocalic gestures tend to be weaker in syllable initial position and stronger in syllable final position" (p. 305). The relationship between these two gestures shows that the consonantal apical gesture is attracted to syllable margins, while the vocalic dorsal gesture is attracted to syllable nuclei. In terms of the gestures' timing, it was found that the apical gesture occurs slightly before the vocalic gesture in producing the syllable initial /1/. Both gestures end almost simultaneously. To produce the syllable final $/ 1 /$, the dorsal gesture occurs much earlier than the apical gesture. The end of the dorsal guesture is almost synchronous with the beginning of the apical gesture (Browman \& Goldstein, 1995). The above descriptions of the English /1/ are abstracted in Figure 1.
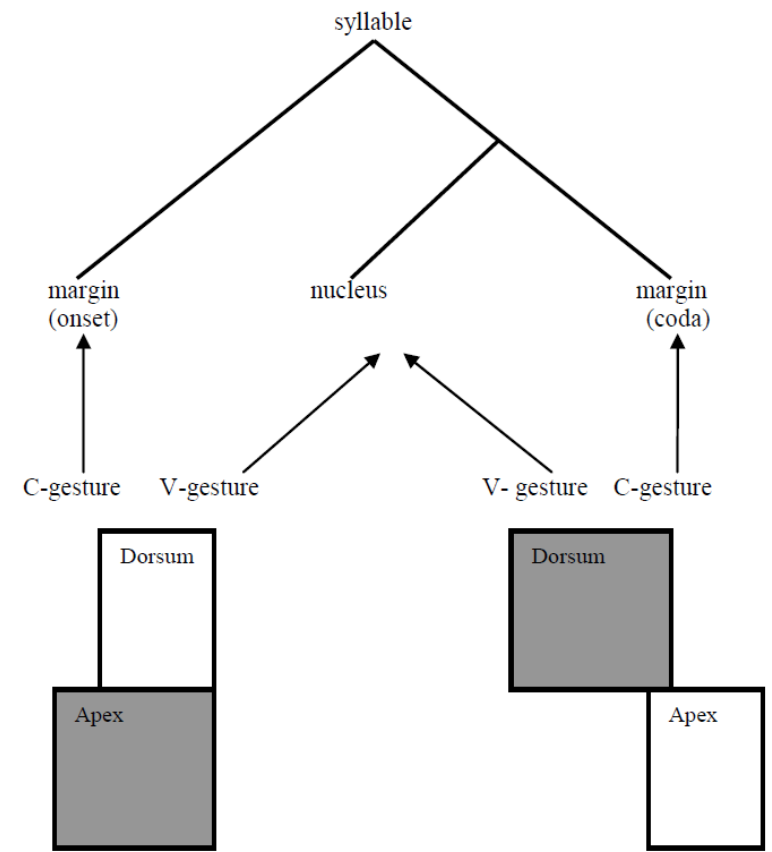

Figure 1. Schematic view of Sproat and Fujimura's (1993) and Browman and Goldstein's (1995) gestural account of /1/ in English. Shaded boxes represent stronger gestures. (Revised version of the diagram in Carter, 2003; p78)

\section{Research Questions}

The present study was conducted to investigate the production of English /1/ in syllable final position by Mandarin speakers and aimed to answer the following questions:

1. How well do Mandarin speakers produce the singleton syllable-final /l/? In other words, what are the variations of /l/, if any, typically produced by Mandarin speakers?

2. What strategies do Mandarin speakers use to modify or approximate English syllable-final /l/?

3. What are the factors that may prevent native Mandarin speakers from producing English syllable- final /1/ accurately?

4. How do linguistic and other factors (such as social factors) affect the way Mandarin speakers modify English syllable-final /1/?

\section{MEthodology}

\section{A. Participants}

Eight Mandarin speakers (4 male and 4 female) in Victoria, Canada, and eight Mandarin speakers (4 male and 4 female) in Beijing, China, participated in this experiment. All were university students, and all were native speakers of the Northern dialects of Mandarin. They ranged from 20 to 30 in age, and had been taught English in a formal educational environment from junior high school through university for over 10 years. All subjects were free from any medically significant speech or hearing problems.

The eight Mandarin speakers residing in Canada constituted the experienced group of speakers. They all had been in Victoria for at least one year, and were all over the age of 16 when they first arrived. They all had previously passed the 
Test of English as a Foreign Language (TOEFL) with a minimal score of 550, the minimum score required for an international student to enter the university. They all had taken undergraduate or graduate courses instructed in English at the University of Victoria and had communicated with local people in English on a regular basis.

The eight Mandarin speakers in China comprised the inexperienced group. All were graduate students in Materials Engineering at the Beijing University of Science and Technology. None had ever been to an English-speaking country prior to participating in the study. The English instruction they received in class was focused on reading and writing abilities, and they seldom used English to communicate with others outside their English classes.

\section{B. Stimulus Materials}

Two tasks were used to elicit the ESL data in two speech styles: reading a word list and reading a mini dialogue. In the word-list reading task, forty English words in the syllable pattern CVL were used. All of them were real words. The vowels in the tested words were $/ \mathrm{I} /, / \varepsilon /, / \mathrm{o} /$ and $/ \mathrm{u} /{ }^{1}$. Each vowel occurred ten times in various consonantal environments in each unit of the task. There were a total of 640 tokens in the word-list reading task $(10 \mathrm{CVL} \times 4$ vowels $\times 16$ participants $=640$ tokens $)$.

In the mini-dialog reading task, two dialogues were prepared containing the target words with syllable-final /1/. The target words all occurred at the end of phrases or sentences. In other words, all of them occurred before a pause, creating a rhyming pattern in the dialogues. The purpose of this arrangement was to minimize differences from the effects of the following environment. The results of the pronunciations of three of the words in the dialogues were not considered: the name Phil when it occurred the first time in the first dialogue, the word well when it occurred the second time in the first dialogue and the person's name Paul when it occurred the first time in the second dialogue. This is because the pronunciation of syllable-final /1/ in the words Phil and well might be influenced by the syllable-initial $/ 1 / \mathrm{s}$ at the beginnings of the following words, look and let, respectively. If the speaker speaks quickly, the two adjacent words will be linked together. The syllable-final /1/ of the word Phil would be changed into the syllable-initial /1/ of the word look. The same process of assimilation could also apply to the syllable-final /1/ in the word well. Therefore, the accuracy rate of these tokens could potentially be higher than that of other tokens with syllable-final /l/ following a front vowel. The name Paul was followed by the word would which begins with the glide /w/, which, in turn, might trigger vocalization of syllable-final /1/. Therefore, the accuracy of the token could potentially be lower than others with the syllable-final /1/ following a back vowel. A total of 304 tokens from the mini-dialogue reading task were analyzed (5 $\mathrm{C} / \_/ \mathrm{L} \times 16$ participants $+4 \mathrm{C} / \varepsilon / \mathrm{L} \times 16$ participants $+5 \mathrm{C} / \curvearrowright / \mathrm{L} \times 16$ participants $+5 \mathrm{C} / \mathrm{u} / \mathrm{L} \times 16$ participants $=304$ tokens).

\section{Procedure}

During the word-list reading task, the subjects were tested one at a time in a quiet room. At first, the subject heard accurate productions of the test words, presented by an experienced phonetician, an adult female native English speaker. This step ensured that the subject received the correct input. Then, the subject did a trial reading in order to become familiar with the words. After that, the subject read the word list. The productions were recorded into a computer using PRAAT.

In the mini-dialog reading task, the procedure was similar to that of the preceding experiment. First, the subjects heard accurate production of the test sentences presented. Then they were asked to translate the English dialogues into Mandarin in order to force them to focus their attention on the meaning of the content rather than just the pronunciation of the words. After that, they read the dialogues as if they were a natural conversation.

\section{Judgment}

The elicited data were judged in two ways, by native speakers and/or by Praat. Two native speakers of Canadian English were asked to identify whether the /1/s produced by the Mandarin speakers were identical to the ones made by the native English speaker. If an /// did not match native production, the judges were instructed to indicate how the /1/ was pronounced (or mispronounced). If the judges were not in agreement in their transcriptions, an acoustic analysis was performed with PRAAT, which was used to generate spectrograms for tokens. What was supposed to be the dark /l/ was identified in the following ways:

Phoneme /1/: The F2 drifts downward in frequency, indicating a back tongue position. The F3 drifts upward, indicating a movement of the tip of the tongue towards the alveolar ridge.

Vocalized /1/: The F2 lowers, as the tongue position is relatively back and the lips are relatively rounded, and the F2 angle towards the vowel is steeper than with the syllable-final /1/. F3 does not show a rising tendency.

Deleted /1/: The F2 and F3 of the vowel in the nucleus do not change after finishing the production of the target word.

Retroflexed /1/: F3 lowers and F2 rises, which indicates that the tip of the tongue curls.

\section{RESUlTS AND DiSCUSSION}

\section{A. Error Rate}

\footnotetext{
${ }^{1}$ Mandarin participants in this study tended to lengthen the short vowels / I/ and / / in their production, so the length of preceding vowels was not taken into account.
} 


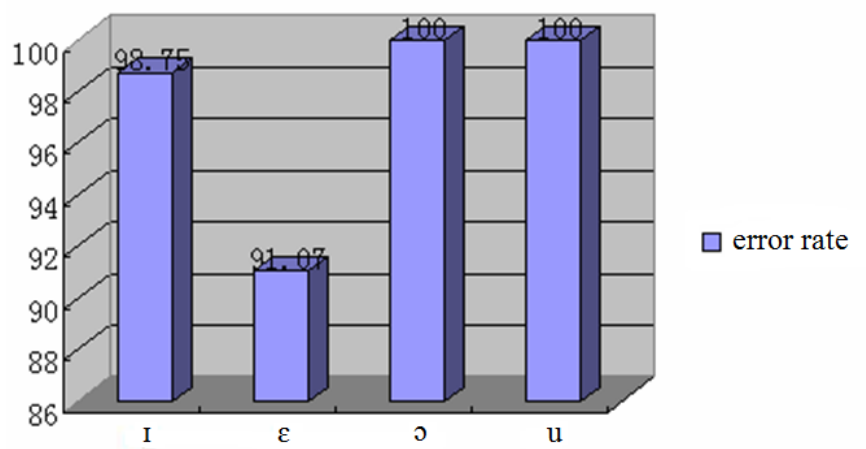

Figure 2. Error rates of production of the syllable final /1/ with different preceding vowels in word list and mini-dialogue tasks

Figure 2 clearly shows that Mandarin speakers had difficulties in producing /1/ correctly in syllable final position. The error rate for syllable final /l/ is extremely high, averaging $97 \%$ in all vowel contexts. The error rates for syllable final $1 /$ after different vowels are all above $90 \%$. Two reasons can be employed to explain these phenomena. Let us consider L1 phonological influence first. In Mandarin, the phoneme /1/ cannot occur in syllable final position. Mandarin only allows nasal consonants $/ \mathrm{n} /$ and $/ \mathrm{y} /$ and retroflex $/ \mathrm{r} /$ in coda position. No other consonant or consonant cluster is permitted in coda position. Therefore, Mandarin speakers might find it difficult to pronounce the /l/ in a new syllable position.

However, this is not an entirely convincing explanation as to why Mandarin speakers cannot produce syllable-final /1/ correctly. Certain other consonants also occur only in syllable initial position in Mandarin, but they are still pronounced with a high accuracy rate by Mandarin speakers when they occur in syllable final position in English. For example, over $80 \%$ of the syllable final voiceless stops in Hansen's (2001) study were pronounced correctly by Mandarin speakers. Therefore, the new syllable position is not a sufficient explanation for this phenomenon. Thus, we should take phonetic influence into account as well. Syllable final /1/ is not only different from syllable initial /// in syllable position, but also different in manner of articulation that does not apply to voiceless consonants. The phoneme /1/ has two articulatory gestures: consonantal apical gesture and vocalic dorsal gesture. Both of these are oral gestures, whereas the voiceless stops have only one oral gesture (Browman \& Goldstein, 1995). Furthermore, the oral gestures of the /1/ can be considered as two lingual gestures which no other consonants in English (except $/ \mathrm{r} /$ ) have. Therefore, the articulation of the phoneme /l/ is more 'complex' (Gick, 2004). Also, there is a time lag between the two lingual gestures of syllable final /l/, whereas the two gestures occur almost simultaneously in producing syllable-initial /l/. Since simultaneous gestures are easier to produce (Kelso et al., 1979), syllable-initial /1/ is easier to produce than syllable final /1/. In sum, Mandarin speakers' difficulty in pronouncing syllable final /1/ correctly is due to the fact that /1/ does not occur in the position in Mandarin syllable structure patterns, and to the manners of coarticulation of the phoneme /1/. Although syllable-final /l/ is almost always mispronounced by Mandarin speakers, a small percentage of $/ 1 / \mathrm{s}$ following the mid front vowel $/ \varepsilon /$ are pronounced correctly. The reason for this relatively higher accuracy will be discussed in the next section.

\section{B. Error Type}

In addition to error rate, error types were further investigated. Three strategies were found: vocalization, deletion, and retroflexion, which are defined as follows:

Vocalization: The apical gesture is lost and the dorsal gesture is maintained. As a result, the vocalized /1/s were heard as a back vowel such as $/ \mathrm{u} /$ or $/ \mathrm{o} /$.

Deletion: The two gestures of articulation of /1/ are totally lost, leaving no consonantal segment in coda position.

Retroflexion: The tip of the tongue is curled behind but not touching the alveolar ridge. The /1/s were perceived more as the retroflexed $/ \mathrm{r} /$.

TABLE 1 .

VARIATIONS IN VOCALIZATION

\begin{tabular}{|c|c|c|c|c|}
\hline & \multicolumn{4}{|c|}{ Preceding vowel } \\
\hline & 1 & $\varepsilon$ & $\mathrm{u}$ & 0 \\
\hline Type of vocalization & /ou/ & $/ \mathrm{o} /, / \mathrm{u} /$ & $/ \mathrm{o} /, / \mathrm{ou} /$ & $/ \mathrm{u} /$ \\
\hline Exception & $/ \mathrm{u}^{\mathrm{r}} /, / \mathrm{\gamma} /$ & $/ \mathrm{u}^{\mathrm{r}} /, / \mathrm{r} /$ & -- & --- \\
\hline
\end{tabular}

As shown in Table 1, various vowels were substituted for the syllable final /1/ in the production test. The vowel /ou/ consistently replaced syllable final /l/ when the vocalization of /1/ occurred after the vowel / / . The vowels /u/ or /o/ were used to modify the /l/ when the vocalization of $/ \mathrm{l} /$ occurred after the vowel $/ \varepsilon /$. The vowel /o/ or /ou/ substituted for the /l/ when the vocalization happened after the vowel /u/. There were exceptions, however: Ten tokens ended with the vowel / $/$ / after the front vowel / / , and ten tokens with / $/$ after the front vowel / $\varepsilon /$. Five tokens ended with /ur/ after the vowel / / and eighteen tokens ended with $/ \mathrm{u}^{\mathrm{r}} /$ after the vowel / $\varepsilon$ /. 
TABLE 2 .

\begin{tabular}{|l|l|}
\multicolumn{2}{|c|}{ LINGUISTIC AND SOCIAL FACTORS UNDER INVESTIGATION } \\
\hline Categories & Factor groups \\
\hline Linguistic & Vowel backness \\
& High front vowel / / \\
& Mid front vowel / $\varepsilon /$ \\
& High back vowel /u/ \\
& Mid back vowel /o / \\
\hline Social & Gender \\
& Female \\
& Male \\
& Experience \\
& Experienced (Chinese students in Canada) \\
& Inexperienced (Chinese students in China) \\
& Style \\
& Formal style (word list reading) \\
& Casual style (mini-dialogue reading) \\
\hline
\end{tabular}

Shown in Table 2, several linguistic and social factors which may affect the Mandarin speakers' use of strategies for modifying syllable final /1/ are also considered. The production results are presented according to these different factors.

In the following tables, the letter $\mathrm{L}$ was used for correct production of the phoneme $/ 1 / \mathrm{V}$ for vocalization, $\mathrm{R}$ for retroflex $/ \mathrm{r} /$, and $\mathrm{D}$ for deleted $/ \mathrm{l} /$.

1. The effect of vowel backness

TABLE 3.

PERCENTAGES OF OCCURRENCES OF VOCALIZATION, RETROFLEXION, AND DELETION WHEN THE SYLLABLE FINAL /L/ OCCURS AFTER DIFFERENT VOWELS, WITH THE NUMBERS OF TOKENS IN PARENTHESES

\begin{tabular}{|c|c|c|c|c|}
\hline \multicolumn{5}{|c|}{ Preceding Vowels } \\
\hline & $1 / 1$ & $/ \varepsilon /$ & $/ \mathrm{u} /$ & $10 /$ \\
\hline $\mathrm{L}$ & $1.25(3)$ & $8.9(20)$ & $0(0)$ & $0(0)$ \\
\hline V & $98.75(237)$ & $91.1(204)$ & $17.9(43)$ & $37.5(90)$ \\
\hline $\mathrm{R}$ & $0(0)$ & $0(0)$ & $13.8(33)$ & $16.7(40)$ \\
\hline $\mathrm{D}$ & $0(0)$ & $0(0)$ & $69.3(164)$ & $45.8(110)$ \\
\hline Total & $100(240)$ & $100(224)$ & $100(240)$ & $100(240)$ \\
\hline
\end{tabular}

The row of correct productions shows that Mandarin speakers had great difficulties pronouncing /1/ after any vowel, especially after the back vowels $/ \mathrm{u} /$ and $/ 0 /$. We can also see that Mandarin speakers used the same strategy of vocalization to modify the syllable final /l/ which occurred after both of the front vowels / / and / $\varepsilon /$. They used three different strategies to modify the /l/ after the back vowels /u/ and /o /.

The strategy of deletion was most frequently employed in these two cases. The vocalization strategy came next, and the retroflexion strategy was the one least used to modify syllable final / $/$ after $/ \mathrm{u} / \mathrm{and} / \mathrm{o} /$. Comparing the percentages of vocalization of syllable final /l/ after the vowels $/ \mathrm{u} /$ and $/ \mathrm{o} /$, it was found that the percentage of vocalization after the vowel /o / was twice as great as the percentage of vocalization after the vowel /u/. The difference between the occurrences of deletion to modify the $/ \mathrm{l} /$ after the vowels $/ \mathrm{u} /$ and $/ \mathrm{o} / \mathrm{is}$ also significant, $\mathrm{t}=4.798, p<.05$.

This kind of modification can be explained by phonological influence and phonetic influence. Two types of phonological influence predispose vocalization: one is universal syllable structure, and the other is Mandarin syllable structure. The universally least marked syllable structure is the CV syllable (Yavas 1994). Vocalizing the /1/ in coda position can be attributed to the effect of universal preference for open syllables. After being vocalized, the CVL pattern becomes CVV, which is an open syllable. Furthermore, no consonants are permitted in syllable final position in Mandarin, except nasal /n/, /n/, and retroflexed /r/. Therefore, L1 syllable structure patterns enhance the high probability of Mandarin speakers' choosing the strategy of vocalization. Different from stops, which attract an epenthetic schwa to form an extra CV structure (Hansen, 2001; Lin 2001), syllable-final /1/ has articulatory manners which make it possible for $/ 1 /$ itself to be vocalized rather than being attached with a vowel. As mentioned before, syllable-final /l/ has two articulatory gestures, a consonantal apical gesture and a vocalic dorsal gesture. In syllable final position, the vocalic gesture tends to be stronger and the consonant gesture tends to be weaker. The vocalic gesture also occurs before the consonantal gesture in producing syllable-final /l/ (Sproat \& Fujimura 1993; Browman \& Goldstein 1995). Therefore, it is more likely for Mandarin speakers to lose the consonantal gesture and maintain the vocalic gesture in syllable final position. The tip of the tongue of the Mandarin speakers might not touch or approach the alveolar ridge to produce an extreme obstruction after the dorsum of the tongue retracts.

Now we need to consider why the vowels $/ \mathrm{u} /$ and $/ \mathrm{o} /$ (and sometimes their diphthong) are selected to be the substitutes for syllable-final /1/. The two vowels share the features of [+back, +round]. According to articulatory phonology, /u/ and /o / have two articulation gestures. One is a lip gesture; the other is a dorsal gesture. When speakers pronounce these two vowels, their lips become round and the dorsum of their tongue retracts. Thus, the vowels cause the dorsal gesture of syllable-final /l/ to be retained and the apical gesture of syllable-final /l/ to be lost. Also, / $/$ / and /o / have only one lingual gesture, the dorsal gesture. Therefore, the back vowels show a pattern of "lingual simplification" (Gick, 2004). Due to the advantages of similarity of dorsal shape with syllable-final /l/ and the simpler 
manner of pronunciation, /u/ and / / are chosen to modify syllable-final /l/. However, phonetic influence cannot explain the strong preference for one vowel over the other to modify syllable-final /l/ when it follows different vowels, such as $/ / /, / \varepsilon /, / \mathrm{u} /$ and $/ \mathrm{o} /$. To account for this, we need to look back to the influence of the L1 phonology. In the Mandarin vowel system, the monophthongs /i/, /o / and /u/, the diphthong /ou/ and the triphthong /iou/ exist. The vowel / $\varepsilon$ / only occurs after the vowels /i/ and /y/. No back vowels can follow the vowel $/ \varepsilon /$.

The Mandarin speakers' tendency to transfer their L1 phonological structures to their L2 yields the vowel /ou/ after the vowel /i/ (Here, Mandarin speakers change the vowel / / to the vowel /i/), and the vowel /u/ after the vowel /o / in the vocalization process. The reason why the vowels $/ \mathrm{o} /$ and /ou/ are preferred to modify syllable-final / $/ /$ after the vowel $/ \mathrm{u} /$ is quite straightforward: In order to make a segment sound like a syllable-final /l/ and also sound different from the nucleus, the vowel $/ \mathrm{o} / \mathrm{is}$ chosen rather than the vowel $/ \mathrm{u} /$. The diphthong /ou/ is created by the closing procedure of the monophthong $/ \mathrm{o} /$.

Since there is no Mandarin syllable pattern that has a diphthong like $/ \varepsilon \mathrm{u} / \mathrm{or} / \varepsilon \mathrm{o} /$, there should be no L1 syllable structure transfer to influence Mandarin speakers' choice between the vocalization options / $\mathrm{u} /$ and /o/. Therefore, Mandarin speakers choose either of these vowels to modify syllable-final /1/. The relatively high accuracy rate of syllable-final /l/ after the vowel $/ \varepsilon /$ produced by Mandarin speakers can also be attributed to the lack of negative transfer of L1 phonological structure.

An interesting substitution was observed in two of the Mandarin speakers. They substituted / $\mathrm{u}^{\mathrm{r}} /$ to modify syllablefinal $/ \mathrm{l} /$ after the vowels $/ \mathrm{I} /$ and $/ \varepsilon /$. The substitute's first articulation feature is the back rounded vowel /u/, and its second articulation feature is the retroflex $/ \mathrm{r} /$. This means that when the speakers tried to produce the target segment, the posterior body of the tongue retracted, the lips rounded and the tip of the tongue curled. The sound $/ \mathrm{u}^{\mathrm{r}} /$, with $\mathrm{three}$ gestures, is more difficult to produce than the liquid /1/, with two gestures. The source of making such a complex and difficult sound might be sought in the influence of Mandarin syllable structure. In Mandarin, the retroflexed /r/ can be attached to the back vowels $/ \mathrm{u} /$ and /o/ as a secondary articulation (Duanmu, 2000). These two speakers tried to produce the dorsal gesture of /1/, but also rounded their lips.

Meanwhile, they misproduced the consonantal gesture of /1/ by retroflexing the tip of the tongue rather than extending it to the alveolar ridge. Another of the Mandarin speakers consistently produced syllable-final /1/ as a back unrounded vowel / $/$ / after a front vowel / / or $/ \varepsilon /$. This is not a unique way of modifying syllable-final /l/. In African American English, a similar central vowel /ə/ is used to substitute for syllable-final /1/, as in bea [beə] for 'bell' and pia [piə] for 'pill' (Green, 2002; p. 120). The speaker may have noticed that the target /1/ has no lip rounding gesture, but still failed to produce the apical gesture. Therefore, the dorsum of his tongue retracted but without rounding of his lips.

It was found that the preceding vowels / I / and /\&/ are strong inhibitors of deletion, while the preceding vowels /u/ and / / promote deletion. This may be due to 'laziness' of articulation. Since the dorsum of the tongue is already retracted in order to produce the preceding vowel /u/ or / /, Mandarin speakers might not find it necessary, in this circumstance, to raise the tip of the tongue towards the alveolar ridge to make a constriction in the vocal tract just to produce the apical gesture of syllable-final /1/. Therefore, the /1/ is deleted. Another explanation for the deletion of /1/ is the perceptual difficulty of hearing syllable-final /1/ when it occurs after back vowels. Mandarin speakers might not hear the /1/ after back vowels, and ignore the $/ 1 /$ in their production. A future study needs to be conducted to prove the perceptual motivation for the deletion of $/ 1 /$.

2. Effects of L2 experience

TABLE 4

PERCENTAGES OF OCCURRENCES OF VOCALIZATION, RETROFLEXION, DELETION AND BY STUDENTS WITH DIFFERENT LEVELS OF ENGLISH EXPERIENCE, WITH THE NUMBERS OF TOKENS IN PARENTHESES

\begin{tabular}{|c|c|c|c|c|c|}
\hline $\begin{array}{l}\text { Preceding Vowels } \\
\text { L2 experiences }\end{array}$ & & / / / & $/ \varepsilon /$ & $/ \mathrm{u} /$ & 101 \\
\hline \multirow[t]{5}{*}{ Experienced } & $\mathrm{L}$ & $1.7(2)$ & $8.9(10)$ & $0(0)$ & $0(0)$ \\
\hline & V & 98.3 (116) & $91.1(102)$ & $11.7(14)$ & $42.5 .5(52)$ \\
\hline & $\mathrm{R}$ & $0(0)$ & $0(0)$ & $14.1(17)$ & $2.5(2)$ \\
\hline & $\mathrm{D}$ & $0(0)$ & $0(0)$ & $74.2(89)$ & $55(66)$ \\
\hline & Total & $100(120)$ & $100(112)$ & $100(120)$ & $100(120)$ \\
\hline \multirow[t]{5}{*}{ Inexperienced } & $\mathrm{L}$ & $0.8(1)$ & $8.9(10)$ & $0(0)$ & $0(0)$ \\
\hline & $\mathrm{V}$ & $99.2\left(119^{2}\right)$ & $91.1\left(102^{3}\right)$ & $24.1(29)$ & 31.7 (38) \\
\hline & $\mathrm{R}$ & $0(0)$ & $0(0)$ & $13.4(16)$ & 31.7 (38) \\
\hline & $\mathrm{D}$ & $0(0)$ & $0(0)$ & $62.5(75)$ & $36.6(44)$ \\
\hline & Total & $100(120)$ & $100(112)$ & $100(120)$ & $100(120)$ \\
\hline
\end{tabular}

Obviously, the inexperienced Mandarin speakers used the retroflexed /r/ to substitute for syllable final /1/ more frequently than the experienced Mandarin speakers did, $\mathrm{t}=6.007, p<.05$. The difference between the percentages of occurrence of deletion between the experienced group and the inexperienced group was not as obvious as in the case of retroflexion. It was, however, still shown to be significant, $\mathrm{t}(238)=2.861, p<.05$. There was no statistically

\footnotetext{
${ }^{2}$ Ten tokens ended with the back vowel $/ \curlyvee /$. Five tokens ended with $/ \mathrm{u}^{\mathrm{r}} /$

${ }^{3}$ Ten tokens ended with the back vowel $/ \gamma /$. Eighteen tokens ended with $/ \mathrm{u}^{\mathrm{r}} /$
} 
significant difference in the percentages of occurrences of vocalization between these two groups, $\mathrm{t}(238)=1.732, p$ $>.05$.

Unlike the strategies of vocalization and deletion, which do not change the lexical meaning of the original English words, retroflexion might change the meaning of words when syllable-final $/ \mathrm{l} /$ is changed into syllable final $/ \mathrm{r} /$, as in pool-poor. Therefore, the strategy of retroflexion can be a potentially confusing way to modify the /1/. This strategy is "dangerous" for effective communication because it might produce a lexical misunderstanding for listeners. The types of errors made by the inexperienced group are less intelligible than those of the experienced group, as we might expect. Therefore, we can see that the experience of living in an English-speaking country helps people to pronounce syllablefinal /1/ more like the English /1/.

3. Effects of gender

TABLE 5 .

PERCENTAGES OF OCCURRENCE OF VOCALIZATION, RETROFLEXION, DELETION AND BY GENDER, WITH THE NUMBERS OF TOKENS IN PARENTHESES

\begin{tabular}{|c|c|c|c|c|c|}
\hline $\begin{array}{l}\text { Preceding Vowels } \\
\text { Gender }\end{array}$ & & / / / & $/ \varepsilon /$ & $/ \mathrm{u} /$ & / / / \\
\hline \multirow[t]{5}{*}{ Female } & $\mathrm{L}$ & $2.5(3)$ & 17 (19) & $0(0)$ & $0(0)$ \\
\hline & $\mathrm{V}$ & 97.5 (117) & $83(93)$ & $35(42)$ & $49.2(59)$ \\
\hline & $\mathrm{R}$ & $0(0)$ & $0(0)$ & $7.5(9)$ & $8.3(10)$ \\
\hline & $\mathrm{D}$ & $0(0)$ & $0(0)$ & $57.5(69)$ & $42.5(51)$ \\
\hline & Total & $100(120)$ & $100(112)$ & $100(120)$ & $100(120)$ \\
\hline \multirow[t]{5}{*}{ Male } & $\mathrm{L}$ & $0(0)$ & $1(1)$ & $0(0)$ & $0(0)$ \\
\hline & $\mathrm{V}$ & $100(120)$ & 99 (111) & $0.8(1)$ & $25(31)$ \\
\hline & $\mathrm{R}$ & $0(0)$ & $0(0)$ & $20(24)$ & $25(30)$ \\
\hline & $\mathrm{D}$ & $0(0)$ & $0(0)$ & $79.2(95)$ & $50(59)$ \\
\hline & Total & $100(120)$ & $100(112)$ & $100(120)$ & $100(120)$ \\
\hline
\end{tabular}

There was a significant difference between males and females in the frequency of accurate production of syllable final $/ 1 /, \mathrm{t}=4.437, p<.05$. Also, the chi-square test shows that gender does have an effect Mandarin speakers' choices of strategies to modify syllable final $/ \mathrm{l} /$ after the vowel $/ \mathrm{u} /, \chi^{2}(2)=50.033, p<.05$, and after the vowel /o/, $\chi^{2}(2)$ $=19.293, p<.05$. We can see that females did not use the strategy of retroflexion as frequently as males did. Female speakers more frequently vocalized syllable final $/ \mathrm{l} /$ after the vowels $/ \mathrm{u} /$ and /o/. The difference between the percentages of occurrence of deletion after the vowel $/ \mathrm{u} /$ between females and males is significant, $\mathrm{t}=3.614, p<.05$. However, the difference between the genders in percentages of occurrence of deletion after the vowel /o / did not reach a significant level, $\mathrm{t}=1.165, p>.05$.

As mentioned in the linguistic factors section, retroflex $/ \mathrm{r} /$ as a substitution for syllable-final $/ \mathrm{l} /$ is more consistent with a "Chinese accent" than other substitutions. Therefore, we can say that female Mandarin speakers outperformed male Mandarin speakers in pronouncing syllable-final /l/. Previous research has shown females to be less conservative than males, and more open to linguistic influences from the society of target language (Watt and Milroy, 1999; p. 41). Therefore, females have more chances to perceive English input and produce output of English and are more likely to benefit from these chances. It has also been found that female L2 speakers tend to show higher frequencies of using proper or standard forms of speech and pronunciation than males (Gussenhoven, 1979; Leather and James, 1996; Broeder, 1982). The present study can be regarded as further evidence that females have more chances to acquire Standard English pronunciation, and pay more attention to using it. The males, on the other hand, do not seem to be as concerned about their accent as much as the females do; therefore, their errors in pronunciation of syllable-final /l/ are more accented.

4. Effects of style

TABLE 6.

PERCENTAGES OF OCCURRENCE OF VOCALIZATION, RETROFLEXION, DELETION AND IN DIFFERENT READING STYLES, WITH THE NUMBER OF TOKENS IN PARENTHESES

\begin{tabular}{llllll}
\hline $\begin{array}{l}\text { Preceding Vowels } \\
\text { Style }\end{array}$ & & / / / & / / $/$ / & / / \\
\hline Formal & $\mathrm{L}$ & $0.6(1)$ & $10.6(17)$ & $0(0)$ & $0(0)$ \\
& $\mathrm{V}$ & $99.4(159)$ & $89.4(143)$ & $23.1(37)$ & $43.7(70)$ \\
& $\mathrm{R}$ & $0(0)$ & $0(0)$ & $15.6(25)$ & $16.9(27)$ \\
& $\mathrm{D}$ & $0(0)$ & $0(0)$ & $61.3(98)$ & $39.4(63)$ \\
& Total & $100(160)$ & $100(160)$ & $100(160)$ & $100(160)$ \\
Casual & & & & $0(0)$ & $0(0)$ \\
& $\mathrm{L}$ & $2.5(2)$ & $4.7(3)$ & $7.5(6)$ & $25(20)$ \\
& $\mathrm{V}$ & $97.5(78)$ & $95.3(61)$ & $10(8)$ & $16.25(13)$ \\
& $\mathrm{R}$ & $0(0)$ & $0(0)$ & $82.5(66)$ & $58.75(47)$ \\
& $\mathrm{D}$ & $0(0)$ & $0(0)$ & $100(80)$ & $100(80)$ \\
\hline
\end{tabular}

Using a t-test, we did not find a significant difference in error rates in production of syllable final /// between formal and casual styles, $\mathrm{t}=1123, p>.05$. However, the chi-square test shows that style does have an effect on Mandarin 
speakers' preferred strategies for modifying syllable final $/ 1 /$ after the vowel $/ \mathrm{u} /, \chi^{2}=12.019, p<.05$, and after the vowel $/ 0 /, \chi^{2}=9.381, p<.05$. There is a significant difference in the degree of use of certain strategies when modifying syllable final $/ \mathrm{l} /$ after back vowels. Mandarin speakers are more likely to vocalize the $/ \mathrm{l} /$ after the vowel $/ \mathrm{u} /, \mathrm{t}=2.972, p$ $<.05$, and the vowel $/ \mathrm{o} /, \mathrm{t}=2.821, p<.05$, in the formal style than in the casual style. Meanwhile, the occurrences of deletion in the formal style were significantly increased over those in the casual style for syllable final /l/ after the vowels $/ \mathrm{u} /, \mathrm{t}=3.329, p<.05$, and $/ \mathrm{o} / \mathrm{t}=3.634, p<.05$. There was a significant threefold increase in the deletion of syllable final /l/ after the vowel /o / in the style shift from casual to formal. There was no significant difference between the percentages of occurrence of the retroflexion strategy in the two styles, either after the vowel $/ \mathrm{u} /, \mathrm{t}=1.168, p>.05$, or after the vowel $/ \mathrm{o} / \mathrm{t}=0.127, p>.05$.

Several studies (Broselow et al., 1998; Major, 1994; Weinberger, 1987) have compared production of consonants or consonant clusters in different speech styles. Using formal and casual parameter of speech style, three production styles were considered. From the most formal degree to the most casual degree, the order of the three styles is: word list reading (minimal pair reading), sentence reading (paragraph reading), and storytelling (conversation). The "formal equals accurate" axiom proposes that L2 learners achieve greater accuracy or produce more native-like output as their speech style becomes more formal. However, the present study did not find that the error rate in production of syllable final /l/ increased when the reading style shifted from word list reading to mini-dialogue reading. In other words, Mandarin speakers in the study did not produce more correct tokens of the /1/ when the reading style was more formal. However, the study found that a significant change took place when the reading style became formal. The syllable final /1/ after back vowels was more frequently vocalized or retroflexed in the word list reading task. Since there was no linguistic context in the word list environment, speakers paid attention to the spelling of the word and made every segment clearly audible. According to the sonority sequence hierarchy (SSH), vowels and retroflex /r/ are more sonorous than liquid /1/. Therefore, the Mandarin speakers chose vowels and retroflex /r/ in order to make their "/1/" more salient.

\section{CONCLUSION}

This is the first study to look at the production of English /// in syllable final position by adult speakers of Mandarin Chinese. It was found that Mandarin speakers do have difficulties in pronouncing the $/ 1 /$ in syllable final positions and show many variations in their modification of the English /1/ in the syllable positions. Furthermore, it provides an explanation as to why Mandarin speakers employ their modification strategies from phonological and phonetic perspectives.

\section{APPENDIX}

1. Word list

\begin{tabular}{|l|l|l|l|l|l|l|l|l|l|}
\hline bill & hill & kill & till & bill & kill & till & bill & kill & hill \\
\hline bell & cell & dell & tell & sell & bell & dell & tell & sell & bell \\
\hline cool & pool & fool & tool & pool & cool & fool & pool & tool & cool \\
\hline ball & fall & mall & tall & call & fall & wall & ball & mall & hall \\
\hline
\end{tabular}

2. Two mini-dialogues (tested words in bold)

Dialogue One

A: Hi Phil! Look at my laptop. It is a Dell.

B: Well! That's swell, Bill! For how much did it sell?

A: It is a real steal. See the bill.

B: Cool deal! Phil. I want to buy one as well! Let's call.

Dialogue Two

A: Paul, would you like to play basketball?

$\mathrm{B}$ : Me? Look at me. I am not that tall. I can't play basketball. I cannot play at all.

A: You're so dull. You're not cool.

B: You're so cruel. Are you thinking I'm a fool? I am not a fool! At school, I'm cool!

\section{REFERENCES}

[1] Aoyama, K., Flege, J.E., Guion, S. G., Akahane-Yamada, R., \& Yamada, T. (2004). Perceived phonetic distance and L2 learning: The case of Japanese /r/ and English /1/ and /r/. Journal of Phonetics, 32(2), 233-250.

[2] Aoyama, K. (2003). Perception of syllable-initial and syllable-final nasals in English by Korean and Japanese speakers. Second Language Research,19 (3), 251-265.

[3] Borden, G., Gerber, A \& Milsark, G. (1983). Production and perception of the /r/-/l/ contrast in Korean adults learning English. Language Learning, 33(3), 499-526.

[4] Bradlow, A., Pisoni, D., Yamada, R., \& Tohkura, Y. (1997). Training Japanese listeners to identify English /r/ and /1/: IV. Some effects of perceptual learning on speech production. Journal of the Acoustical Society of America, 101, 2299-2310. 
[5] Broeders, A. (1982). Engels in nederlandseoren: Uitspraakvoorkeur bij nederlands estudenten engels in Toegepaste Taalkunde in Artikelen (pp. 127-128). Amsterdam: Vu Boekhandel.

[6] Browman, C. P., \& Goldstein. L. (1995). Articulatory phonology: An overview. Phonetica, 49, 155-180.

[7] Duanmu, San. (2000). The phonology of Standard Chinese. Oxford: Oxford University Press.

[8] Gick, B. (2004). Responding to physical constraints on speech production. Paper presented at the Department of Linguistics Colloquium Series, the University of Victoria, February, 2004.

[9] Green, L. (2002). African American English: a linguistic introduction. Cambridge [UK]; New York: Cambridge University Press.

[10] Goto, H. (1971) Auditory perception by normal Japanese adults of the sounds "l" and "r", Neuropsychologia, 9, $317-323$.

[11] Gussenhoven, C. (1979). Pronunciation preference among Dutch students. Paper presented at the Second International Conference on the Teaching of Spoken English, University of Leeds.

[12] Hansen, J. G. (2001). Linguisitic constraints on the Acquisition of English syllable codas by native speakers of Mandarin Chinese. Applied Linguistics, 22, 338-365.

[13] Heselwood, B., \& McChrystal, L. (2000). Gender, accent features and voicing in Panjabi-English bilingual children. Leeds Working Papers in Linguistics and Phonetics, 8, 45-70.

[14] Kelso, J. A. S., Southard, D. L. \& Goodman, D. (1979) On the nature of human interlimb coordination. Science 203: 1029-1031.

[15] Leather, J., \& James, A. (1991). The acquisition of second language speech. Studies in Second Language Acquisition, 13(3), 305-341.

[16] Lee, M. (1976). Pronunciation problems are different and similar among Cantonese and Mandarin speakers. TESL Reporter, 9(4), Sum, 3-6.

[17] Lin, H. (2001). A Grammar of Mandarin Chinese, Munich: Lincom Europa.

[18] Major, R. C. (1994). Chronological and stylistic aspects of second language acquisition of consonant clusters. Language Learning, 44, 655- 680.

[19] Major, R. C. \& Faudree, M. (1996). Markedness in second language acquisition of consonant clusters. In R. Bayley \& D. Preston (Eds.), Second Language Acquisition and Linguistic Variation (pp. 97-120). John Benjamin B.V.

[20] Major, R. C., \& Kim, E. (1999). The similarity differential rate hypothesis. Language Learning, 49, supplement 1, $151-183$.

[21] Oh, S. (2002). Cross-language blending of /1/ gestures by Korean-English bilingual children. 26th Boston University Conference on Language Development (BUCLD), 2, 473-484.

[22] Schmidt, A., \& Meyer, K. (1995). Traditional and phonological treatment for teaching English fricatives and affricates to Koreans. Journal of Speech and Hearing Research, 38, 828-838.

[23] Sheldon, A., \& Strange, W. (1982). The acquisition of /r/ and /1/ by Japanese learners of English: evidence that speech production can precede speech perception. Applied Psycholinguistics, 3, 243-261.

[24] Sproat, R. \& Fujimura, O. (1993) Allophonic variation in English /1/ and its implications for phonetic implementation. Journal of Phonetics, 21(3), July 291-311.

[25] Wang, C. (1995). The acquisition of English word-final obstruents by Chinese speakers. PhD dissertation, State University of New York at Stony Brook.

[26] Whalen, Best \& Irwin. (1997). Lexical effects in the perception and production of American English /p/ Allophones. Journal of Phonetics, 25(4), 501-528.

[27] Weinberger, S. (1987). The influence of linguistic context on syllable simplification, In Gioupand S. \& Weinberger (Eds.), Interlanguage phonology: The acquisition of second language sound system (pp. 401-417). Rowley, MA: Newbury House.

[28] Watt, D., \& Milroy, L. (1999). Phonetic variation in three Tyneside vowels: Is this dialect leveling? In P. Foulkes and G. J. Docherty (Eds.) Urban voices: Accent Studies in the British Isles (pp. 25-46). London: Arnold.

[29] Yavas, M. (1994). Final stop devoicing in interlanguage. In M. Yavas (Ed.), First and second language phonology (pp. 267282). San Diego, CA: Singular.

[30] Yeon, S. (2004), Perception of English palatal codas by Korean speakers of English. Journal of Pan-Pacific Association of Applied Linguistics, 8, 110-123.

Yunjuan He is Assistant Professor of Chinese at the University of North Georgia in the United States of America. She received her $\mathrm{PhD}$ in linguistics from the University of Florida, USA. Her research interests are second language acquisition from phonological and phonetic perspectives, Chinese pedagogy and sociolinguistics. 